University of Nebraska - Lincoln

DigitalCommons@University of Nebraska - Lincoln

Faculty Publications -- Chemistry Department Published Research - Department of Chemistry

March 2004

\title{
Magnesium/Methanol: An Effective Reducing Agent for Peroxides
}

Peng Dai

Patrick Dussault

University of Nebraska-Lincoln, pdussault1@unl.edu

Tony K. Trullinger

Follow this and additional works at: https://digitalcommons.unl.edu/chemfacpub

Part of the Chemistry Commons

Dai, Peng; Dussault, Patrick; and Trullinger, Tony K., "Magnesium/Methanol: An Effective Reducing Agent for Peroxides " (2004). Faculty Publications -- Chemistry Department. 1.

https://digitalcommons.unl.edu/chemfacpub/1

This Article is brought to you for free and open access by the Published Research - Department of Chemistry at DigitalCommons@University of Nebraska - Lincoln. It has been accepted for inclusion in Faculty Publications -Chemistry Department by an authorized administrator of DigitalCommons@University of Nebraska - Lincoln. 
J. Org. Chem., 69 (8), 2851 -2852, 2004. 10.1021/jo035191d S0022-3263(03)05191-0

Web Release Date: March 12, 2004

Copyright (C) 2004 American Chemical Society

\title{
Magnesium/Methanol: An Effective Reducing Agent for Peroxides
}

\author{
Peng Dai, Patrick H. Dussault, $\underset{-}{*}$ and Tony K. Trullinger \\ Department of Chemistry, University of Nebraska-Lincoln, Lincoln, Nebraska 68588- \\ 0304 pdussault1@unl.edu
}

Received August 14, 2003

\begin{abstract}
:
Magnesium in methanol is an effective reagent for the chemoselective reduction of peroxides, including ozonides. $\mathrm{Mg} / \mathrm{MeOH}$ is significantly more reactive than $\mathrm{Me}_{2} \mathrm{~S}$ or $\mathrm{PPh}_{3}$ and somewhat more reactive than $\mathrm{Zn} / \mathrm{HOAc}$.
\end{abstract}

The American Chemical Society allows the posting of only the title, abstract, tables, and figures from articles appearing in the Journal of Organic Chemistry.

This article is published online (for subscribers) at http://pubs.acs.org/cgi-bin/abstract.cgi/joceah/2004/69/i08/abs/jo035191d.html

A 21 -page pdf file of "Supporting Information" is available (free to all users) at http://pubs.acs.org/cgi-bin/suppinfo.pl?jo035191d

figures (3) follow 


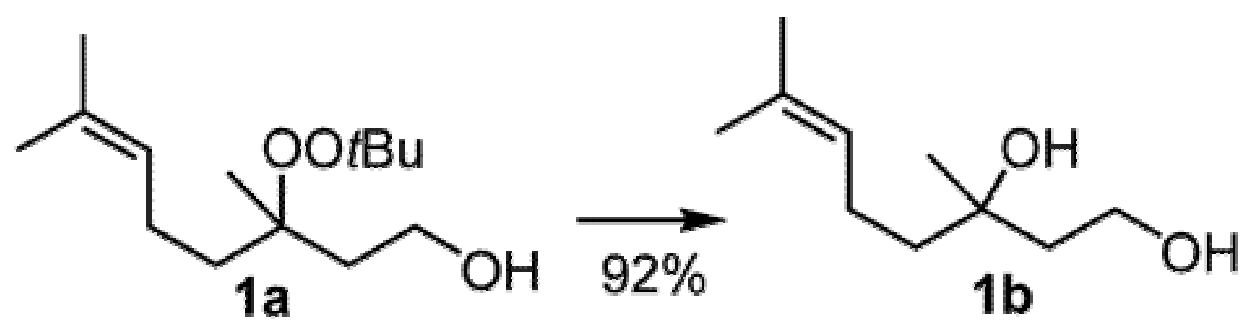<smiles>[Y]C(=O)CC1(C)CC(C)(C)OO1</smiles>

2a: $X=S E t$

3a: $X=O M e$

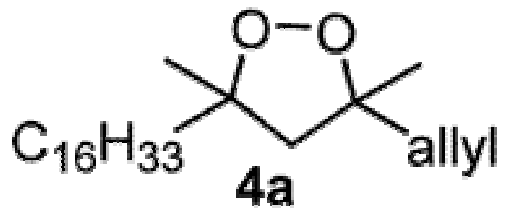<smiles>CC(O)CC([13CH3])([13CH3])[13CH3]</smiles>

$5 a$<smiles>[O]C1CCCCO1</smiles>

$6 a$<smiles>CC1CCC(C2(C)OCOO2)CC1=O</smiles>

$7 a$

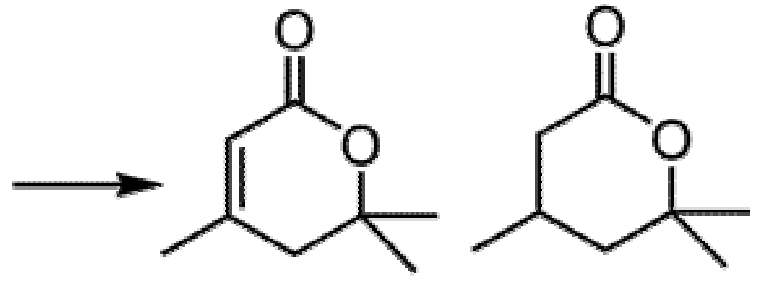

2b $\begin{array}{lll}73 \% & \text { 2c } & 0 \% \\ 7.5 \% & & 75 \%\end{array}$

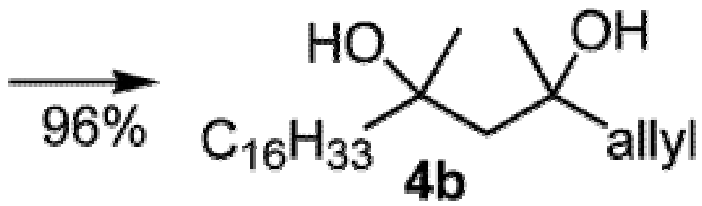
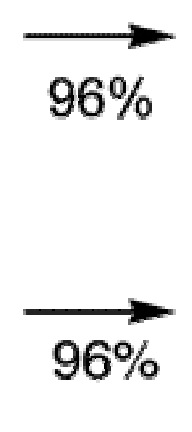<smiles>CC(=O)C1CCC(C)C(=O)C1</smiles>

$7 b$

Scheme 1. Reductions with $\mathrm{Mg} / \mathrm{MeOH}^{a}{ }^{a} \mathrm{Mg}$ (5.0 equiv), $40^{\circ} \mathrm{C}, 3 \mathrm{~h}$.

Copyright (C) 2005 American Chemical Society 



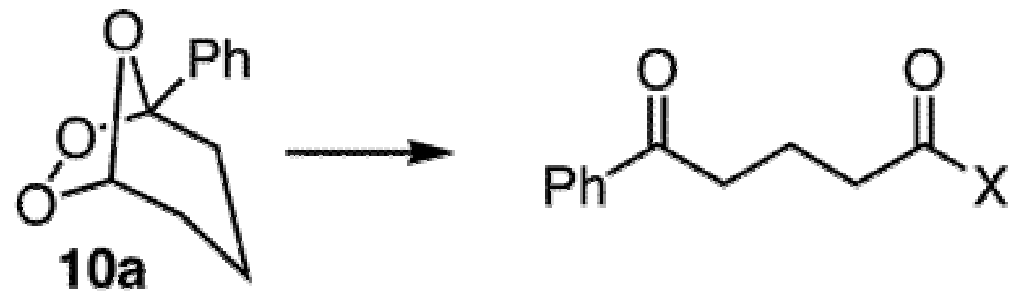

\begin{tabular}{lccc} 
Reagent & $\begin{array}{c}10 \mathrm{~b} \\
(\mathrm{X}=\mathrm{H})\end{array}$ & $\begin{array}{c}\text { 10c } \\
(\mathrm{X}=\mathrm{OH})\end{array}$ & $\begin{array}{c}\text { 10d } \\
(\mathrm{X}=\mathrm{OMe})\end{array}$ \\
\hline $\mathrm{Zn} / \mathrm{HOAC}$ & 86 & 8 & 0 \\
$\mathrm{Mg} / \mathrm{MeOH}$ & 0 & 70 & 12
\end{tabular}

Copyright (C) 2005 American Chemical Society 

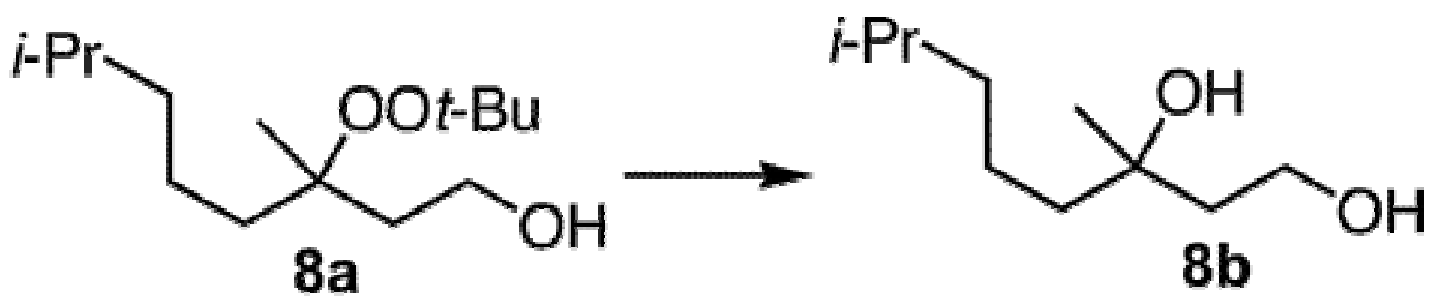

\begin{tabular}{lllll} 
Reagent & Solvent & \multicolumn{1}{l}{$\mathrm{T}\left({ }^{\circ} \mathrm{C}\right)$} & \multicolumn{1}{l}{$\mathrm{t}(\mathrm{h})$ yield } \\
\hline $\mathrm{Zn}(5 \mathrm{eq})$ & $\mathrm{HOAC}$ & $\mathrm{RT}$ & 18 & $18 \%(80 \% 8 \mathrm{a})$ \\
$\mathrm{Zn}(20 \mathrm{eq})$ & $\mathrm{HOAC}$ & $\mathrm{RT}$ & 36 & $29 \%(65 \% 8 \mathrm{a})$ \\
$\mathrm{Mg}(5 \mathrm{eq})$ & $\mathrm{MeOH}$ & 40 & 3 & $94 \%$
\end{tabular}
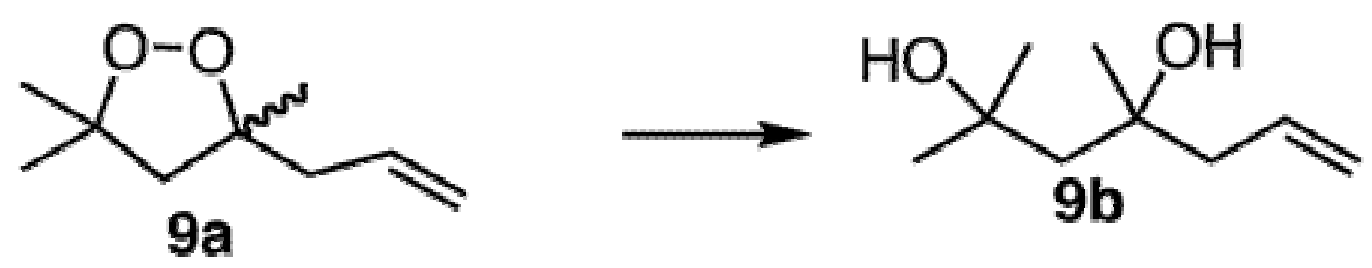

\begin{tabular}{lllll} 
Reagent & Solvent & $\mathrm{T}\left({ }^{\circ} \mathrm{C}\right)$ & $\mathrm{t}(\mathrm{h}$ & Yield \\
\hline $\mathrm{PPh}_{3}$ & $\mathrm{CH}_{2} \mathrm{Cl}_{2}$ & $\mathrm{RT}$ & 48 & $-(92 \% 9 \mathrm{a})$ \\
$\mathrm{Me}_{2} \mathrm{~S}$ & $\mathrm{CH}_{2} \mathrm{Cl}_{2}$ & $\mathrm{RT}$ & 48 & $-(85 \% 9 \mathrm{a})$ \\
$\mathrm{Zn}(5 \mathrm{eq})$ & $\mathrm{HOAC}$ & $\mathrm{RT}$ & 18 & $80 \%$ \\
$\mathrm{Mg}(5 \mathrm{eq})$ & $\mathrm{MeOH}$ & 40 & 3 & $73 \%$
\end{tabular}

Scheme 2. Comparison with Other Reducing Agents

Copyright (C) 2005 American Chemical Society 